\title{
Evangélicos e a sociedade em rede As eleições de 2018 e 0 impacto das redes sociais no Brasil ${ }^{1}$
}

\author{
Nelson Lellis Ramos Rodrigues ${ }^{2}$
}

\section{RESUMO}

Ao analisar a partir de autores e autoras que laboram acerca do fenômeno religioso voltado para a esfera virtual e seus desdobramentos que perpassam a mística e as relações interpessoais o presente artigo aborda essa presença de religiosos no campo das redes sociais em relação à política brasileira, delimitada aqui nas eleições presidenciáveis de 2018. Com o advento da internet, é possível afirmarmos, baseados em Castells, que a audiência tornou-se mais seletiva devido à multiplicidade de mensagens e fontes. As pessoas acessam aquilo que lhes interessa. E, segundo pesquisa divulgada pelo IBGE, a transmissão da mensagem é a principal finalidade de acesso à internet. Este relatório pretendeu, a partir da análise de dados divulgados por institutos de pesquisas, compreender como religiosos, através de redes sociais, tiveram participação efetiva na candidatura de Jair Bolsonaro à presidência do Brasil.

\section{PALAVRAS-CHAVE}

Religião. Política. Eleições. Redes sociais.

\footnotetext{
1 O presente trabalho foi realizado com apoio da Coordenação de Aperfeiçoamento de Pessoal de Nível Superior - Brasil (CAPES). Agradecimento à CAPES pelo fomento de bolsa no Programa de Pós-Graduação em Sociologia Política na Universidade Estadual do Norte Fluminense Darcy Ribeiro.

2 Doutorando em Sociologia Política pela Universidade Estadual do Norte Fluminense Darcy Ribeiro (Uenf); mestre em Ciências das Religiões, especialista em Ensino Religioso e graduado em Teologia pela Faculdade Unida de Vitória-ES. Membro do Grupo de Pesquisa DT-Crelig (Dinâmicas Territoriais, Cultura e Religião).
} 


\begin{abstract}
In analyzing authors and authors working on the religious phenomenon focused on the virtual sphere and its unfolding that cross mysticism and interpersonal relations, this article addresses the presence of religious in the field of social midias in relation to Brazilian politics, delimited here in the presidential elections of 2018. With the advent of the internet, it is possible to affirm, based on Castells, that the audience has become more selective due to the multiplicity of messages and sources. People access what interests them. And, according to research released by the IBGE, the transmission of the message is the main purpose of Internet access. This report intends, from the analysis of data released by research institutes, to understand how religious, through social networks, had an effective participation in the candidacy of Jair Bolsonaro to the presidency of Brazil.
\end{abstract}

\title{
KEYWORDS
}

Religion. Politics. Elections. Social midias.

\section{Introdução}

O IBGE (Instituto Brasileiro de Geografia e Estatística) divulgou os dados de 2016, levantados pela Pnad C (Pesquisa Nacional por Amostra de Domicílios Contínua), onde $64,7 \%$ da população brasileira tem acesso à internet. Em outros números, são 116,1 milhões de pessoas - acima de 10 anos - conectadas. $^{3}$

Em 2017, o número aumentou para 126,4 milhões (69,8\%). O salto foi considerável no ano seguinte, segundo Adriana Beringuy, analista do IBGE: "É um avanço bem expressivo e ocorreu em todos os grupos etários, com mais intensidade entre os idosos"4. O ano de 2018 registrou

\footnotetext{
3 Disponível em: <https://www.ibge.gov.br/estatisticas-novoportal/sociais/rendimento-despesa-e-consumo/9171-pesquisa-nacional-por-amostra-de-domicilios-continua-mensal.html?=\&t=o-que-e $>$. Acesso em: 20 de mar. de 2019.

4 Disponível em: <https://g1.globo.com/economia/tecnologia/noticia/2018/12/20/numero-de-internautas-cresce-em-cerca-de-10-milhoes-em-um-ano-no-brasil-aponta -ibge.ghtml>. Acesso em: 20 de mar. de 2019.
} 
um acréscimo de 10 milhões de novos usuários. Outro aspecto da pesquisa informou que a principal finalidade de acesso é o envio de mensagens (texto e/ou voz) por redes sociais e diferentes aplicativos de e-mails $(95,5 \%){ }^{5}$

Não é a intenção investigar o motivo do avanço em relação aos números de brasileiros que acessam à internet, mas no que isso tem resultado na sociedade, como já destacaram autores como Almeida e Montero (2001), Dawnson (2005), Højsgaard e Warburg (2005), Hoover e Echchaibi (2012), Shoji (2007), Avellar (2009), Aguiar (2010), Jungblut (2010), Alencar (2011), Spadaro (2012), Sbardelotto (2013), Souza (2014), Avellar e Silveira (2014), Carletti (2016), Silva (2016). Estes e muitos outros laboram acerca dos aspectos do fenômeno religioso (também) voltados para a esfera digital e seus desdobramentos que perpassam a mística e as relações interpessoais, o que tem permitido diferentes tipologias para o estudo do tema.

O objetivo é abordar a participação de evangélicos na esfera virtual em relação à política brasileira, delimitada aqui nas eleições presidenciáveis de 2018, bem como interpretar o engajamento de uma parte desses religiosos nas redes sociais cuja finalidade é o acesso e transmissão de mensagens políticas.

Com o advento da internet, é possível afirmarmos, baseados em Manuel Castells ${ }^{6}$ - sociólogo espanhol e um dos pioneiros sobre os estudos dos reflexos da sociedade em rede a partir do fenômeno da internet $-^{7}$, que a audiência tornou-se mais seletiva devido à multiplicidade de mensagens e fontes. As pessoas acessam aquilo que lhes interessa. Em outras palavras, o que lhes apetece será o foco e objetivo não apenas de leitura, mas de transmissão da mensagem que, segundo pesquisa divulgada pelo IBGE, é a principal finalidade de acesso à internet.

Castells ainda observa que não se trata apenas de uma virtualidade, mas de uma construção de uma "realidade virtual". Por outro lado,

5 Disponível em: <https://g1.globo.com/economia/tecnologia/noticia/2018/12/20/numero-de-internautas-cresce-em-cerca-de-10-milhoes-em-um-ano-no-brasil-aponta -ibge.ghtml>. Acesso em: 20 de mar. de 2019.

6 CASTELLS, Manuel. A sociedade em rede. Vol. I. São Paulo: Paz e Terra, 2005.

7 CASTELLS, Manuel. A galáxia da internet. Rio de Janeiro: Zahar Editores, 2003.

8 CASTELLS, 2005, p. 459. 
Sbardelotto ${ }^{9}$ diz que a internet não é uma nova realidade, e sim, uma extensão da mesma que permite diferentes maneiras de se relacionar com o outro (on-line e off-line). Essas constatações nos permite problematizar o deslocamento do(s) sentido(s) dos símbolos religiosos para a esfera virtual. Neste sentido, os símbolos religiosos que são deslocados para o virtual como reais, têm tido êxito nas transformações no âmbito da política brasileira, como demonstraram as eleições de 2018.

Este relatório pretende, portanto, a partir da análise de dados divulgados por institutos de pesquisas, compreender como alguns religiosos evangélicos tiveram participação efetiva na candidatura de Jair Bolsonaro à presidência do Brasil.

\section{Engajamento político de evangélicos nas redes}

Ainda não temos como mensurar o volume de pessoas que debate política nas redes sociais e em aplicativos diversos legitimando suas posições a partir de conteúdo religioso. Por ora, apenas alguns indicativos. Sobre a vivência da fé fora das instituições, pesquisas de Fernandes ${ }^{10}$ e Lellis ${ }^{11}$ apontaram, respectivamente, que a maioria entre jovens e adultos saiu de suas igrejas por causa de regras morais e discordâncias políticas, todavia, pouquíssimos aqueles que se engajaram em partidos e/ou movimentos políticos. Nas pesquisas de Lellis, a partir de grupo focal com evangélicos desinstitucionalizados, as redes sociais foram o ambiente escolhido para vivenciarem, debaterem e divulgarem notícias sobre política a partir de suas percepções de fé. Considerando tais pesquisas, o que podemos apontar é: quando o assunto "religião e política" passa pela "desinstitucionalização da crença" ${ }^{2}$, o indivíduo busca grupos virtuais para debater e promover suas ideias e ideais.

9 SBARDELOTTO, M. E o verbo se fez bit: experiência religiosa na era digital. Aparecida: Editora Santuário, 2013, p. 15.

${ }^{10}$ FERNANDES, Silvia R. Alves. Sem religião e identidades religiosas: notas para uma tipologia. Interseções [UERJ], v. 10, n. 1, 2008, p. 31-46.

${ }^{11}$ LELLIS, Nelson. Indicadores que tipifican evangélicos sin afiliación religiosa: análisis cualitativo a partir de grupo focal. Trabalho apresentado em: XIX Jornadas sobre alternativas religiosas en América Latina, 2018.

12 BERGER, Peter. Os múltiplos altares da modernidade: rumo a um paradigma da religião numa época pluralista. Petrópolis: Ed. Vozes, 2017. 
Em linhas gerais, como sinônimo de desinstitucionalização, o sociólogo alemão Arnold Gehlen emprega o termo "subjetivização"13. Qualquer instituição para ele é um programa de comportamento que faz o indivíduo agir espontaneamente após a interiorização de seus estatutos. Na instituição religiosa, há uma regulação do comportamento até que este se torne habitual, seja tomado como normativo, correto. Gehlen entende que a transição à decisão subjetiva leva o indivíduo a uma "instituição secundária" (ou "instituições fracas"), onde levará consigo algumas características da "instituição forte" (religião) com maior liberdade para outros ambientes, grupos ${ }^{14}$ - e em nossa percepção, no ambiente virtual.

Para a socióloga francesa Danièle Hervieu-Léger, "a crença escapa totalmente ao controle institucional"15 e esse processo de mudança da religião é compreendido por ela como "desregulação institucional", onde "as recomposições das identidades religiosas [...] se inscrevem sobre o duplo signo da proliferação e disseminação das crenças de uma parte e

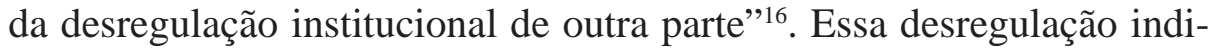
ca novo ethos sobre o religioso. Sua característica é marcada tanto pela emoção quanto por sua presença em diversos setores, inclusive, para esta pesquisa, nas redes sociais, aplicativos e afins. O que ela chama de "desregulação institucional", que também contempla a bricolagem religiosa, pode ser percebido - também - com o termo "desigrejado", cuja responsabilidade com a instituição religiosa e seus estatutos inexiste ou é ressignificado. Desde já é importante destacar que o termo "desregulação institucional" abrange muito mais do que o grupo dos "sem igreja".

Com o avanço dos "sem-igreja" no Brasil, a área das ciências humanas não pode se furtar da contínua observação deste fenômeno. Teixeira e Menezes fizeram a análise do grupo dos "evangélicos não determinados" comparando os Censos de 2000 e 2010. O referido grupo teve um salto estatístico que configura uma recomposição da identidade religiosa

13 GEHLEN, citado por Berger, 2017, p. 77-78.

14 GEHLEN, citado por Berger, 2017, p. 90.

15 HERVIEU-LÉGER, Danièle. O peregrino e o convertido: a religião em movimento. Petrópolis: Vozes, 2008, p. 42.

${ }^{16}$ Hervieu-Léger, citado por TEIXEIRA, Faustino; MENEZES, Renata. Religiões em Movimento: O censo de 2010. Petrópolis: Ed. Vozes, 2013, p. 263. 
e, consequentemente, tomará novos rumos, sendo a internet, impreterivelmente, um deles.

O universo "evangélicos não determinados", sem vínculo institucional, com múltipla pertença ou não determinados: de um pouco mais de 700 mil foram para mais de 8 milhões. Isto é, de 3,8\% dos evangélicos passaram para 23,9\% destes, ou quase, 1 em cada 4 evangélicos não se identifica com nenhuma instituição especificamente ${ }^{17}$.

A política brasileira tem sido marcada com a participação cada vez mais intensa seja de religiosos cristãos ligados às suas instituições, seja por aqueles que são alvos da "desregulação institucional". E isso, em pelo menos 3 setores:

1) No Congresso Nacional (deputados e senadores). ${ }^{18}$

2) Em manifestações populares (engajamento político-social). ${ }^{19}$

3) $\mathrm{Na}$ esfera virtual (redes sociais, aplicativos, e-mails).

É neste último ponto que temos nos concentrado. Retornando a Castells, a virtualidade real consegue absorver "toda a experiência humana, passado, presente e futuro" ${ }^{20}$. Em sua concepção, a lógica comunicativa virtual consegue enfraquecer o poder simbólico das mídias tradicionais (televisão, rádio) que tenham, inclusive, conteúdo religioso. Quando as mensagens de religiosos são transferidas para as redes sociais, aplicativos e e-mails (novas mídias), torna seu poder exponencial. Na "sociedade presentista" [ou "momento imediato"] ${ }^{21}$, a interação e a doutrinação

17 TEIXEIRA e MENEZES, 2013, p. 324.

18 A sociedade assume um papel onde os números progridem neste quesito, tendo em vista que o envolvimento com a profissionalização da política (WEBER, 1971; 2016) não era assunto nem espaço para muitos desses religiosos (BITTENCOURT FILHO, José. Caminhos do protestantismo militante: ISAL e Conferência do Nordeste. Vitória-ES: Unida, 2014).

${ }^{19}$ PY, Fábio; LELLIS, Nelson (orgs.). Religião e Política à Brasileira: ensaios, interpretações e resistência no país da política e da religião. São Paulo: Terceira Via, 2018.

${ }^{20}$ CASTELLS, 2005, p. 459.

${ }^{21}$ BURITY, Joanildo. Sintomas e máscaras do milenarismo numa sociedade presentista. In: Anais do Encontro anual da ANPOCS, XXIV, Petrópolis, 2000. 
são muito mais eficientes através destes canais do que a "transmissão pelo contato direto da distante autoridade carismática"22.

$\mathrm{Na}$ leitura de Castells ${ }^{23}$, a tecnologia é utilizada para acentuar a dominação política. A mensagem (discurso) política também ganha potência transcendente. E o que aqui propomos pensar é que um engajamento de alguns evangélicos no discurso político (partidário ou não) através dos mecanismos que o intensificam, podem gerar mudanças e mudar cursos de campanhas eleitorais. Segundo dados trazidos por Gomes, padre jesuíta e doutor em Comunicação, "na Igreja Católica, há setores que vão de A a Z, da extrema direita, de um espiritualismo total, até a extrema esquerda" ${ }^{24}$. Para ele, portais religiosos tendem a criar uma readequação dessas relações - o que indica que a instituição religiosa consegue acessar seus membros através da internet para doutriná-los e, consequentemente, criar "uma forma de espiritualidade ou uma forma de ver religião diferente" 25 .

Não apenas para relações religiosas, mas também políticas, o ambiente virtual tornou-se local de debates, engajamento partidário, críticas sociais e divulgação em massa em prol de determinados candidatos e contra outros, como se verá a seguir.

\section{Campanhas (virtuais) eleitorais nas eleições de 2018}

A campanha eleitoral dos principais presidenciáveis de 2018 foi marcada em 4 setores da área digital/virtual. Abaixo, através de informações por meio da ferramenta Crowdtangle ${ }^{26}$, tempo de propaganda e interações dos candidatos com eleitores:

${ }^{22}$ CASTELLS, 2005, p. 461.

${ }^{23}$ CASTELLS, 2005.

24 Disponível em: <http://www.ihu.unisinos.br/entrevistas/31031-espiritualidade-na -internet-o-surgimento-de-uma-nova-religiao-entrevista-especial-com-pedro-gilberto-gomes>. Acesso em: 20 de mar. de 2019.

25 Disponível em: <http://www.ihu.unisinos.br/entrevistas/31031-espiritualidade-na -internet-o-surgimento-de-uma-nova-religiao-entrevista-especial-com-pedro-gilberto-gomes>. Acesso em: 20 de mar. de 2019. A igreja católica também tem uma diocese virtual, a Partenia $(<\mathrm{http} / /$ www.partenia.org/>), um site que acolhe fiéis de todo mundo e apresenta seu conteúdo em espanhol, alemão, francês, inglês e português.

${ }^{26}$ Disponível em: 〈https://www.crowdtangle.com/>. Acesso em 01 de mar. de 2019. 


\begin{tabular}{|l|c|c|c|}
\hline $\begin{array}{c}\text { Candidatos à } \\
\text { presidência }\end{array}$ & $\begin{array}{c}\text { Seguidores no } \\
\text { Facebook }\end{array}$ & $\begin{array}{c}\text { Seguidores no } \\
\text { Instagram }\end{array}$ & $\begin{array}{c}\text { Seguidores } \\
\text { no Twitter }\end{array}$ \\
\hline Alckmin (PSDB) & 6,80 & 2,40 & 15,5 \\
\hline Amoêdo (Novo) & 18 & 10,3 & 3,40 \\
\hline Bolsonaro (PSL) & 42,30 & 62,30 & 24,6 \\
\hline Boulos (Psol) & 2,90 & 3,7 & 2,30 \\
\hline Ciro (PDT) & 3,6 & 8,1 & 5,30 \\
\hline Daciolo (Patriota) & 1,6 & 2,40 & 1,20 \\
\hline Dias (PODE) & 7,4 & 0,9 & 5,5 \\
\hline Eymael (DC) & 0,1 & 0,03 & 0,4 \\
\hline Goulart Filho (PPL) & 0,1 & 0,03 & 0 \\
\hline Haddad (PT) & 0,4 & 6,80 & 11 \\
\hline Marina (Rede) & & 2,6 & 29,8 \\
\hline Meirelles (MDB) & 1,6 & 0,5 & 1 \\
\hline Vera (PSTU) & 0,1 & 0,2 & 0,3 \\
\hline
\end{tabular}

Somando todos os candidatos, o total de interações nos aplicativos Facebook, Instagram e Twitter, foram, respectivamente: 88 milhões, 83 milhões e 19 milhões (entre os dias 16 de agosto a 5 de outubro de 2018). Bolsonaro, o candidato que foi eleito, teve interação maior no Facebook e no Instagram, sendo que perdeu apenas para Marina no Twitter por uma diferença de 5,2.

Houve uma outra mídia que auxiliou na campanha do candidato eleito do PSL: o WhatsApp. Eleitores de Bolsonaro criaram redes coordenadas no aplicativo para fomentar a campanha eleitoral. Segundo o professor da UFMG, Fabrício Benevenuto, é impossível medir o impacto do conteúdo replicado no WhatsApp. ${ }^{27}$ Disse mais:

Ele [WhatsApp] foi feito para ser reservado. O que fazemos é monitorar grupos cujos links são lançados publicamente para qualquer pessoa entrar. Notamos que a quantidade de informações falsas

\footnotetext{
${ }^{27}$ Disponível em: <https://www1.folha.uol.com.br/poder/2018/10/internet-supera-tv -em-influencia-na-eleicao.shtml>. Acesso em: 20 de mar. de 2019.
} 
e distorcidas é enorme, mas o efeito bolha e as limitações do mensageiro invalidam análises quantitativas. ${ }^{28}$ (Grifo meu)

A Folha destacou que no período eleitoral recebeu 1.339 mensagens pelo aplicativo em questão. $97 \%$ eram informações distorcidas ou falsas. ${ }^{29} \mathrm{O}$ Datafolha ${ }^{30}$ registrou que 6 em cada 10 eleitores de Bolsonaro acessam o WhatsApp para lerem e trocarem mensagens e que $71 \%$ deles possuem contas em redes sociais. E o Monitor do Debate Político da Universidade de São Paulo ${ }^{31}$ informou que os apoiadores do mesmo candidato movimentaram 38 milhões de interações (os conteúdos destas interações traziam temas como: antifeminismo, antipetismo e antimídia).

Tanto em alcance quanto em taxa de engajamento na difusão de conteúdo político e eleitoral, um dos segmentos mais ativos no Whatsapp é o de eleitores de Jair Bolsonaro. No eleitorado do militar reformado, $70 \%$ estão conectados ao Whatsapp, e $31 \%$ repassam informações sobre política e eleições, ou seja, $44 \%$ estão engajados no tema. Entre os eleitores de Haddad, são menos usuários (59\%) e menos compartilhadores (21\%), o que resulta numa taxa de engajamento de $36 \%$. $\mathrm{Na}$ fatia de eleitores indecisos, apenas $42 \%$ contam com o aplicativo, e $7 \%$ costumam compartilhar notícias sobre política e eleição. ${ }^{32}$

O Datafolha ainda aponta que:

Entre os usuários de Whatsapp, $78 \%$ participam de pelo menos um grupo de troca de mensagens. O eleitorado que usa o aplicativo

${ }^{28}$ Disponível em: <https://www1.folha.uol.com.br/poder/2018/10/internet-supera-tv -em-influencia-na-eleicao.shtml>. Acesso em: 20 de mar. de 2019.

29 Disponível em: <https://www1.folha.uol.com.br/poder/2018/10/internet-supera-tv -em-influencia-na-eleicao.shtml>. Acesso em: 20 de mar. de 2019.

${ }^{30}$ Disponível em: <http://datafolha.folha.uol.com.br/opiniaopublica/2018/10/198376524-dos-eleitores-usam-whatsapp-para-compartilhar-conteudo-eleitoral.shtml>. Acesso em: 20 de mar. de 2019.

31 Disponível em: <https://www.monitordigital.org/imprensa/>. Acesso em: 20 de mar. de 2019.

32 Disponível em: <http://datafolha.folha.uol.com.br/opiniaopublica/2018/10/198376524-dos-eleitores-usam-whatsapp-para-compartilhar-conteudo-eleitoral.shtml>. Acesso em: 20 de mar. de 2019. 
também foi consultado sobre o recebimento e envio de conteúdo eleitoral crítico aos dois candidatos que disputam a Presidência, e os resultados mostram que $44 \%$ receberam conteúdo falando mal de Bolsonaro ou de seu partido, e $47 \%$ receberam o mesmo tipo de conteúdo sobre Haddad. No caso de Bolsonaro, 29\% tiveram acesso a esse tipo de conteúdo por meio amigos do aplicativo, $15 \%$, de parentes, e $20 \%$, de desconhecidos. O mesmo tipo de conteúdo sobre Haddad foi enviado por amigos $(31 \%)$, desconhecidos $(22 \%)$ e parentes $(18 \%){ }^{33}$ (Grifo meu)

Pôde-se observar, na mesma pesquisa, que entre os eleitores de Bolsonaro, que venceu as eleições, $52 \%$ acreditavam nas mensagens transmitidas pelo aplicativo. Em outubro de 2018, a jornalista Patrícia Campos Mello publicou a notícia de que empresas estariam comprando pacotes de disparos de mensagens em massa (centenas de milhões) contra o PT (partido do candidato Fernando Haddad). Pela legislação eleitoral, a prática é ilegal, uma vez que se trata de doação de empresas e não declarada. Estando correta a percepção de Castells ${ }^{34}$, as empresas, na sociedade em rede, ocupam-se em sua ganância e os políticos se dedicam em manter o poder.

O contrato chegava a 12 milhões de reais. Segundo a reportagem, a Havan era uma das empresas financiadoras e os valores variavam de $\mathrm{R} \$ 0,08$ a $\mathrm{R} \$ 0,12$ por disparo para a base do candidato e de $\mathrm{R} \$ 0,30$ a $\mathrm{R} \$ 0,40$ quando fornecida por agência. Assim funcionava o chamado "disparo em massa":

As empresas apoiando o candidato Jair Bolsonaro (PSL) compram um serviço chamado "disparo em massa", usando a base de usuários do próprio candidato ou bases vendidas por agências de estratégia digital. Isso também é ilegal, pois a legislação eleitoral proíbe compra de base de terceiros, só permitindo o uso das listas de apoiadores do próprio candidato (números cedidos de forma voluntária) ${ }^{35}$

\footnotetext{
33 Disponível em: <http://datafolha.folha.uol.com.br/opiniaopublica/2018/10/198376524-dos-eleitores-usam-whatsapp-para-compartilhar-conteudo-eleitoral.shtml> . Acesso em: 20 de mar. de 2019.

${ }^{34}$ CASTELLS, 2005.

35 Disponível em: <https://www1.folha.uol.com.br/poder/2018/10/empresarios-bancam-campanha-contra-o-pt-pelo-whatsapp.shtml>. Acesso em: 20 de mar. de 2019.
} 
A Folha ainda relatou que apenas a empresa AM4 Brasil Inteligência Digital consta na prestação de contas do candidato Bolsonaro com a cifra de 115 mil reais, valor exclusivo para mídias digitais.

No dia 12 de novembro de 2018, o WhatsApp informou ao Tribunal Superior Eleitoral (TSE) que não trabalha com impulsionamento de mensagens e que as páginas oficiais de Bolsonaro não contrataram quaisquer serviços durante a campanha eleitoral. ${ }^{36}$ A nota oficial do aplicativo, embora tenha sido aceita pelo TSE, não concluiu o assunto, pois uma coisa é a contratação pelos canais virtuais do candidato eleito, outra são as empresas se sentirem dispostas a se envolverem politicamente (processo eleitoral).

Seguindo a reportagem da Folha de São Paulo, que acompanhou centenas de grupos de eleitores de Bolsonaro, percebeu que a estratégia era replicar conteúdo de apoio ao candidato do PSL e desaprovação ao candidato do PT (com discussões sobre identidade de gênero e outros formatos familiares, comunidade LGBT e seus direitos, feminismo, kit gay, mamadeira de piroca).

Para Castells ${ }^{37}$, a participação em rede acontece a partir de ideologias e motivações diferentes causadas por crise democrática e representatividade política. Seriam os partidos políticos, na interpretação deste sociólogo, que possuem o domínio da "crise" servindo a si mesmos, controlando eleições por dinheiro e pelos meios de comunicação. Mas também entende que a comunicação em rede possibilita formas autônomas de debate e organização online, revitalizando a democracia ao lançar suas críticas às instituições, partidos e políticos corruptos.

\section{Evangélicos (nas redes) e as eleições de 2018}

Nesta última seção perceberemos que os religiosos de que falamos encontram-se, sobretudo, na ala conservadora de algumas igrejas evangélicas.

\footnotetext{
${ }^{36}$ Disponível em: <http://agenciabrasil.ebc.com.br/justica/noticia/2018-11/whatsappdiz-ao-tse-que-nao-foi-contratado-por-campanha-de-bolsonaro>. Acesso em: 20 de mar. de 2019.

${ }^{37}$ CASTELLS, 2015.
} 
Denominações como Assembleia de Deus ${ }^{38}$, Igreja Internacional da Graça de Deus ${ }^{39}$, Igreja Universal do Reino de Deus ${ }^{40}$, dentre outras, expressaram apoio a Bolsonaro nas eleições.

Na Região dos Lagos, um pastor da Igreja Batista enviou um áudio via WhatsApp aos seus seguidores. A revista Época divulgou o conteúdo. Nota-se que todos os três candidatos citados no áudio foram eleitos em 2018:

[...] quero passar uma cola para os irmãos [...]. Penso que Bolsonaro seria um bom presidente. Bolsonaro 17. Segundo, governador do estado do Rio de Janeiro [...], Witzel, vai fazer um bom governo. Para senador, Flávio Bolsonaro, filho do Bolsonaro, $177 .{ }^{41}$ (Grifo meu)

Outras lideranças evangélicas transmitiram notas que não expressavam claramente apoio ao candidato do PSL, mas que demonstravam em quem não se deveria votar, levando em consideração questões morais. Um documento foi assinado por pastores e outros oficiais da Igreja Presbiteriana do Brasil, Igreja Batista, Igreja Cristã da Aliança. Destacaremos alguns pontos da carta: ${ }^{42}$

1. Que o SENHOR, o Deus Triúno, conduza em suas campanhas os candidatos honestos, bem-intencionados, comprometidos com a transparência e a moralidade, com princípios virtuosos de vida em sociedade e com uma visão cristã de mundo, a fim de que estes consigam ser eleitos aos cargos a que concorrem;

\footnotetext{
${ }^{38}$ Disponível em: <http://www.diariodepernambuco.com.br/app/noticia/politica/2018/10/11/interna_politica,765268/psc-ligado-a-assembleia-de-deus-oficializa -apoio-a-jair-bolsonaro.shtml>. Acesso em: 20 de mar. de 2019.

39 Disponível em: <https://congressoemfoco.uol.com.br/eleicoes/lider-da-igreja-internacional-da-graca-de-deus-declara-apoio-a-bolsonaro/> . Acesso em: 20 de mar. de 2019.

${ }^{40}$ Disponível em: <https://www1.folha.uol.com.br/poder/2018/10/ao-apoiar-bolsonaro-edir-macedo-volta-as-origens-antipetistas-e-a-satanizacao-de-lula.shtml >. Acesso em: 20 de mar. de 2019.

${ }^{41}$ Disponível em: <https://epoca.globo.com/a-costura-politica-que-uniu-bolsonaro-aos -evangelicos-23211834>. Acesso em: 20 de mar. de 2019.

42 Disponível em: <https://guiame.com.br/gospel/mundo-cristao/em-carta-igreja-brasileira-lideres-defendem-postura-biblica-diante-das-eleicoes.html>. Acesso em: 19 de mar. de 2019.
} 
2. Que o SENHOR, o Deus Triúno, mude o coração daqueles que estão dispostos a votar em candidatos envolvidos em casos de corrupção, nem permita que estes sejam eleitos;

3. Que o SENHOR, o Deus Triúno, refreie a representação de ideologias anticristãs em nossos parlamentos estaduais e no Congresso Nacional;

4. Que o SENHOR, o Deus Triúno, frustre toda a tentativa de fraude no sistema eleitoral;

5. Que o Senhor, o Deus Triúno, não permita mais confusão e outros atos de violência, a fim de que essas eleições sejam concluídas pacificamente;

6. Que o Senhor, o Deus Triúno, por meio da obra santificadora do Espírito Santo, traga um verdadeiro avivamento à sua Igreja no Brasil, provocando um grande e duradouro impacto cultural, moral e social, por meio de homens e mulheres que produzam frutos dignos de arrependimento.

As expressões em itálico sugerem, pelas generosas fontes jornalísticas inseridas no contexto político-religioso brasileiro, que o candidato "honesto", comprometido com a "moralidade", com a "visão cristã", que sofreu um ato de violência (atentado em Juiz de Fora-MG) e que faz duras críticas ao fomento cultural, moral e social da esquerda (representada pelo candidato Haddad), trata-se de Bolsonaro. E que "ideologias anticristãs" surgiriam do PT ou de outro partido afim.

A carta faz também algumas considerações:

a) Para a escolha de candidato, recomenda-se conhecer bem o seu caráter, ideias e a ideologia do partido;

b) Apoie propostas que defendam a dignidade do ser humano e $a$ vida em qualquer circunstância, desde sua concepção no ventre materno;

c) Rejeite candidatos com ênfases intervencionistas na esfera familiar, educacional, eclesiástica e artística;

d) Repudie qualquer ideologia que se oponha aos princípios do Reino de Deus, isto é, com a mensagem bíblica;

e) Apoie candidatos que expressam compreender a função primordial do Estado em prover e promover justiça e segurança para seus cidadãos;

f) Por fim, ao indicar um candidato para amigos e familiares, faça-o com respeito às opiniões diferentes da sua, lembrando que, 
apesar de você acreditar na pessoa para quem está dando e pedindo voto, como cristãos, nossa esperança última de sociedade perfeita deve estar na consumação dos séculos, quando Jesus voltará para reinar com cetro de justiça.

Ainda que a carta-documento não diga o nome de quem se deve votar, fica mais claro perceber, nestas considerações finais, em quem não se deve votar: aquele que é favorável ao debate democrático sobre a descriminalização do aborto, aos direitos da comunidade LGBT e adjacências, que preza pela laicidade do país, desaprova a lei de armamento na sociedade.

Ao término da carta, solicita-se que todos compartilhem "nas redes sociais e, se possível, peça autorização aos seus pastores para lê-la em sua igreja, seja no culto, escola dominical, pequenos grupos ou demais reuniões" (grifo meu) ${ }^{43}$. Castells observou que como as formas de controle tradicionais estão se esvaindo e o sistema político atual se encontre em crise de legitimidade e representatividade, as novas redes (virtuais) ganham protagonismo pela sua dimensão e potencialização da mensagem. E neste caso, em vista de como os dados foram aqui apresentados, a religião parece (querer) o controle para nortear os rumos eleitorais e, consequentemente, políticos do país.

Tal percepção ganha notoriedade pela pesquisa do sociólogo Alexandre Brasil Fonseca, que disse não ter dúvidas

de que o voto evangélico desempenhou importante papel na vitória de Bolsonaro, especialmente por sua capacidade em atingir setores que na última eleição votaram mais na candidatura do PT à Presidência. A campanha de Bolsonaro assumiu tanto no discurso como em atos práticos uma preferência para com este segmento. ${ }^{44}$

Ainda que Bolsonaro seja católico, sua presença em cultos de igrejas evangélicas e o uso constante de expressões bíblicas durante sua campanha, ajudaram a promover uma empatia considerável entre este segmento

${ }^{43}$ CASTELLS, 2005.

${ }^{44}$ Disponível em: <http://www.ihu.unisinos.br/78-noticias/584446-foram-os-evangelicos-que-elegeram-bolsonaro $>$. Acesso em: 20 de mar. de 2019. 
e o candidato. Não apenas [alguns] líderes evangélicos conservadores tiveram participação ativa durante as eleições. A própria resposta de [alguns] evangélicos progressistas, por meio de petição pública na internet, serve aqui de exemplo. Trata-se da "Carta Pastoral à Nação Brasileira"45, que reuniu teólogos(as), pastores(as), líderes presbiterianos(as), batistas, metodistas, católicos(as) e de outros segmentos. O interesse do manifesto passa pela defesa do Estado laico e, consequentemente, o não uso do nome de Deus em campanhas eleitorais, como considera o item 10: "Nossa defesa do Estado laico, da liberdade de consciência e de expressão, do direito à vida, à maturidade individual e à integridade, e do pleno direito de exercermos a liberdade religiosa" 46 .

\section{Considerações finais}

Toda a participação no mundo virtual mostra-se como real; real não porque o virtual o seja, mas por causar impactos, desdobramentos, consequências na sociedade. A máquina é apenas uma máquina. As redes sociais são apenas redes sociais. São as ações dos indivíduos que modificam estruturas, manejam ideias e fomentam movimentos reais pelas virtuais. Evangélicos em suas participações nas redes sociais ajudam a interpretar a sociedade e diferentes segmentos religiosos, conquanto que obedeçam às seguintes características: acesso do indivíduo aos canais virtuais, como aplicativos, e-mails e semelhantes, com engajamento político como finalidade. Foi o que se pôde perceber nas seções precedentes.

Este artigo não afirmou que a participação de evangélicos nas redes sociais serve como resposta direta e única pelos candidatos eleitos em 2018. Sugerimos uma interpretação a partir das categorias de análise dos teóricos aqui adotados e de estatísticas feitas por institutos de pesquisas. Entendemos sim, que parte de um efetivo grupo de religiosos evangélicos

${ }^{45}$ Disponível em: <https://peticaopublica.com.br/pview.aspx?pi=cartapastoral2018〉. Acesso em 27 de mar. de 2019.

${ }^{46}$ Disponível em: <https://peticaopublica.com.br/pview.aspx?pi=cartapastoral2018〉. Acesso em 27 de mar. de 2019. 
conservadores, que se insere nas redes sociais e aplicativos com interesse de receber e transmitir mensagens políticas, obtiveram resultados positivos nas eleições conforme suas ações no mundo virtual. E isso estabelece uma linha cada vez mais tênue entre a força de religiosos (militantes, partidários ou simplesmente simpáticos a determinado candidato/proposta) no uso de redes sociais e demais eleitores que aguardam maiores informações/desinformações dos candidatos.

\section{Referências}

ALENCAR, Gedeon. Pentecostalismo hi-tech: uma janela aberta, algumas portas fechadas. Revista Eletrônica do Núcleo de Estudos e Pesquisa do Protestantismo da Faculdade EST, n. 26: 43-54, 2011.

AGUIAR, Carlos Eduardo Souza. A sacralidade digital: a mística tecnológica e a presença do sagrado na rede. São Paulo: ECA, 2010.

"Da ciber-religião para a ciber-religiosidade". In:

AVELLAR, V; SILVEIRA, E. (org.). Espiritualidade e sagrado no mundo cibernético. São Paulo: Edições Loyola, 2014.

ALMEIDA, Ronaldo; MONTERO, Paula. Trânsito religioso no Brasil. São Paulo: Perspectiva, vol.15, n.3: 92-101, 2001.

AVELLAR, Valter Luís. Espiritualidade e internet: análise de uma experiência mística através do correio eletrônico. Dissertação de Mestrado em Ciências da Religião - Universidade Católica de Pernambuco. Pró-reitoria Acadêmica, 2009. Disponível em: <http://www.unicap. br/tede/tde_arquivos/5/TDE-2010-05-11T144939Z-288/Publico/dissertacao_valter_luis.pdf $>$.

AVELLAR, V; SILVEIRA, E. (org.). Espiritualidade e sagrado no mundo cibernético. São Paulo: Edições Loyola, 2014.

BERGER, Peter. Os múltiplos altares da modernidade: rumo a um paradigma da religião numa época pluralista. Petrópolis: Ed. Vozes, 2017.

BITTENCOURT FILHO, José. Caminhos do protestantismo militante: ISAL e Conferência do Nordeste. Vitória-ES: Ed. Unida, 2014.

BURITY, Joanildo. Sintomas e máscaras do milenarismo numa sociedade presentista. In: Anais do Encontro anual da ANPOCS, XXIV, Petrópolis, 2000. 
CAMURÇA, Marcelo Ayres. "A sociologia da religião de Danièle Hervieu-Léger: entre a memória e a emoção". In: TEIXEIRA, Faustino (org.). Sociologia da Religião: enfoques teóricos. $4^{\mathrm{a}}$ ed. Petrópolis: Ed. Vozes, 2011, p. 249-267.

CARLLETI, Renan Silva. Religião e internet: como pensarmos a "religião" hoje? Revista Último Andar, n. 29, p. 19-31, 2016.

CASTELLS, Manuel. A galáxia da internet. Rio de Janeiro: Ed. Zahar, 2003.

A sociedade em rede. Vol. I. São Paulo: Paz e Terra, 2005.

2015.

DAWNSON, L.L. "The mediation of religious experience in cyberspace". In: HØJSGAARD, M.; WARBURG, M. Religion and Cyberspace. London: Routledge, 2005.

FERNANDES, Silvia R. Alves. Sem religião e identidades religiosas: notas para uma tipologia. Interseções [UERJ], v. 10, n. 1, p. 31-46, jun./2008.

HERVIEU-LÉGER, Danièle. O peregrino e o convertido: a religião em movimento. Petrópolis: Vozes, 2008.

HØJSGAARD, M. and WARBURG, M. Religion and Cyberspace. London: Routledge, 2005.

HOOVER, S. and ECHCHAIBI, N. The "third space" of digital religions. The Center for Media, Religion, and Culture: University of Colorado Boulder, 2012.

JUNGBLUT, A. L. O uso religioso da Internet no Brasil. PLURA, Revista de Estudos de Religião, vol.1, n ${ }^{\mathrm{o}}$ 1: 202-212, 2010.

JUNGBLUT, Airton Luiz. Os evangélicos brasileiros e a colonização da internet. Ciencias Sociales y Religión/Ciências Sociais e Religião, Porto Alegre, ano 4, n. 4, p. 149-166, out/2002.

LELLIS, Nelson. Indicadores que tipifican evangélicos sin afiliación religiosa: análisis cualitativo a partir de grupo focal. Trabalho apresentado em: XIX Jornadas sobre alternativas religiosas en América Latina, 2018.

MIKLOS, Jorge. Ciber-religião: a construção de vínculos religiosos na cibercultura. São Paulo: Ideias \& Letras, 2012. 
PY, Fábio; LELLIS, Nelson (orgs.). Religião e Política à Brasileira: ensaios, interpretações e resistência no país da política e da religião. São Paulo: Ed. Terceira Via, 2018.

SOUZA, Ronivaldo Moreira de. "O discurso religioso na mídia digital: entre a diversidade e a intransigência". Unitas - Revista Eletrônica de Teologia e Ciências das Religiões [online]. Vitória-ES, vol. 1, jan.jun., 2014, p. 98-110.

SBARDELOTTO, M. E o verbo se fez bit: experiência religiosa na era digital. Aparecida: Editora Santuário, 2013.

SHOJI, R. "Estudos formais e modelos computacionais da religião". In: USARSKI, F. (org.) O espectro disciplinar das Ciência da Religião. São Paulo: Paulinas, 2007.

SILVA, Juliana C. Lima e. "Eu e meu mouse serviremos ao senhor": um olhar antropológico sobre a blogosfera evangélica. Recife. Revista Último Andar, n. 29, 2016.

SPADARO, A. Ciberteologia: pensar o cristianismo nos tempos da rede. São Paulo: Paulinas, 2012.

TEIXEIRA, Faustino; MENEZES, Renata. Religiões em Movimento: O censo de 2010. Petrópolis: Ed. Vozes, 2013.

WEBER, Max. Ensaios de sociologia. $2^{\mathrm{a}}$ ed. Rio de Janeiro: Zahar Ed., 1971. Metodologia das ciências sociais. $5^{a}$ ed. São Paulo: Cortez; Campinas-SP: Editora da Unicamp, 2016.

\section{Sítios eletrônicos:}

$<$ http://agenciabrasil.ebc.com.br/justica/noticia/2018-11/whatsapp-diz -ao-tse-que-nao-foi-contratado-por-campanha-de-bolsonaro >

$<$ https://congressoemfoco.uol.com.br/eleicoes/lider-da-igreja-internacional-da-graca-de-deus-declara-apoio-a-bolsonaro/>

<http://datafolha.folha.uol.com.br/opiniaopublica/2018/10/198376524-dos-eleitores-usam-whatsapp-para-compartilhar-conteudo-eleitoral.shtml>

$<$ https://epoca.globo.com/a-costura-politica-que-uniu-bolsonaro-aos-evangelicos-23211834> 
<https://guiame.com.br/gospel/mundo-cristao/em-carta-igreja-brasileira -lideres-defendem-postura-biblica-diante-das-eleicoes.html>

$<$ https://g1.globo.com/economia/tecnologia/noticia/2018/12/20/numero-de-internautas-cresce-em-cerca-de-10-milhoes-em-um-ano-no-brasil-aponta-ibge.ghtml>

<https://peticaopublica.com.br/pview.aspx?pi=cartapastoral2018>

$<$ https://www.crowdtangle.com/>

$<$ http://www.diariodepernambuco.com.br/app/noticia/politica/2018/10/11/interna_politica,765268/psc-ligado-a-assembleia-dedeus-oficializa-apoio-a-jair-bolsonaro.shtml>

$<$ https://www.ibge.gov.br/estatisticas-novoportal/sociais/rendimentodespesa-e-consumo/9171-pesquisa-nacional-por-amostra-de-domicilios-continua-mensal.html?=\&t=o-que-e>

$<$ http://www.ihu.unisinos.br/entrevistas/31031-espiritualidade-na-internet-o-surgimento-de-uma-nova-religiao-entrevista-especial-com-pedro-gilberto-gomes>

<http://www.ihu.unisinos.br/78-noticias/584446-foram-os-evangelicosque-elegeram-bolsonaro>

<https://www1.folha.uol.com.br/poder/2018/10/internet-supera-tv-em -influencia-na-eleicao.shtml>

<https://www1.folha.uol.com.br/poder/2018/10/ao-apoiar-bolsonaro-edir -macedo-volta-as-origens-antipetistas-e-a-satanizacao-de-lula.shtml>

$<$ https://www1.folha.uol.com.br/poder/2018/10/empresarios-bancamcampanha-contra-o-pt-pelo-whatsapp.shtml>

$<$ https://www.monitordigital.org/imprensa/>

Submetido em: 27/03/2019

Aceito em: 29/05/2019 